\title{
Suggestion and Application of an IFC-based Predefined Specification for Improving Interoperability of the Building Code Checking System
}

\author{
Jungsik Choi ${ }^{1}$, Inhan $\mathrm{Kim}^{2 *}$ and Jongyeon $\mathrm{Bae}^{3}$ \\ ${ }^{123}$ Department of Architecture, Kyung Hee University, Yongin, Korea \\ ${ }^{1}$ jungsikchoi@gmail.com, ${ }^{2}$ ihkim@khu.ac.kr, ${ }^{3}$ jytheodora@gmail.com
}

\begin{abstract}
In the recent paradigm shift of the construction industry where Building Information Modeling (BIM) adoption is growing rapidly one of the most active sectors is building code checking. In many countries using BIM-based e-submission systems for regulation purposes, buildings are checked using open BIM-based Industry Foundation Classes (IFC). However, BIM information can be missing and cause problems when applying standardized IFC data structures in Korea. In addition, problems can exist with data interpretation due to the complexity of Korean regulations, causing quality issues in the building code checking system. The purpose of this study is to suggest a predefined specification for improving interoperability of the building code checking system. To achieve this purpose, the authors have analyzed regulations in Korea to derive Property Set (Pset) objects and properties and have developed a predefined specification based on the derived objects, properties, and IFC data. In addition, the authors have verified the predefined specification using BIM Vision, an IFC viewer program, for checking the interoperability with IFC data values. Creating a predefined specification will minimize the loss of BIM data and increase the interoperability of the building code checking system. This study can contribute to the extension of the building code checking system and to the utilization of the modeling guide.
\end{abstract}

Keywords: Building Information Modeling (BIM), Code Checking, Predefined Specification, Interoperability

\section{Introduction}

Building Information Modeling (BIM) has actively been adopted to support the productivity of the construction industry. Further, public institutions in advanced countries (e.g., the United States [US], United Kingdom, Singapore, and South Korea) have mandated the implementation of BIM in design delivery and promoted automated checking for BIM quality $[1,2]$. These actions have had greatly promoted practices that use BIM. The building industry is a collaborative environment that requires repetitive data exchanges and communication among different domains and applications at a high frequency [3]. BIM technology is an essential element in the construction industry to improve productivity for building life cycles that can generate and manage information all together [4]. Currently, research is being conducted on utilizing BIM to increase work efficiency and maximize application of information.

BIM technology has been utilized increasingly in quantitative ways in the architecture, engineering, and construction (AEC) disciplines [5]. Owing to recently increased requirements for the improvement of qualitative factors in BIM-based design projects, various quality checks are performed using BIM-based checking software. A quality check minimizes unwanted information and errors that occur in the construction process

${ }^{*}$ Corresponding Author 
and reduces the cost and construction period. However, to take advantage of the BIM data that is generated using a variety of BIM modeling tools, a common format is required as a prerequisite for an objective verification method. The quality checking system should be compatible with a variety of modeling software using the international standard of the Industry Foundation Classes (IFC) for neutrality as the IFC is not dependent on a specific software vendor [6].

IFC is an international standard for the interoperability of information from BIM models produced from different design environments. IFC application is possible in a variety of BIM software and is not confined to the format of the program [7]. However, the IFC schema that was developed in the United States and Europe is difficult to utilize directly in Korea. This problem is being solved in buildingSMART by developing techniques such as Property Set (Pset), Model View Definition (MVD) and BIM Collaboration Format (BCF). Pset is used to customize the information a user wants into the IFC schema. MVD supports the compatibility of relevant information with a variety of BIM programs. BCF improves the cooperation of the BIM workflow. However, the support system is inadequate and the defined standard does not exist between the support system and the actual application, resulting in BIM data loss because the system and application have difference data structures.

The purpose of this study is to suggest a predefined specification that uses established information standards and input methods based on the contact information of the IFC's derived objects and properties and an analysis of Korean regulations. Using BIM Vision, an IFC viewer program, verification of the predefined specification was performed. By minimizing the loss of BIM information, the specification increased the interoperability of the information building code checking system.

\section{Background}

\subsection{The Technology of Compatible Information}

Current BIM tools use different data structures and modeling methods leading to interoperability issues between applications [8]. The buildingSMART International has been developing and supporting the Information Delivery Manual (IDM) and standard technologies such as MVD for IFC file interoperability in the construction process [9]. IDM is the definition of the information exchange system used during the building process and MVD is the specification that can be used to define information obtained through the switched IDM programmer [10].

Based on technologies provided by buildingSMART International, the International Code Council (ICC) created the IDM- and the MVD-related regulations [11]. However, due to their development in the United States and Europe, IDM- and MVD-related regulations are difficult to apply to construction processes and information in Korea.

\subsection{The International Research of Building Code Checking}

Building code checking is the most actively applied quality check., is reviewed through national laws, and is based on each country's regulations. The building code checking system was developed using IFC-related information. Research from the last three years was analyzed in the vertex.

João Poças Martins et al. [12] developed the LicA system to examine the plumbing facilities and plumbing equipment of the provisions of Portugal. Martins et al. presented a development plan, a LicAXML format they had developed to save the Pset, and additional attribute information using the IFC format to develop another LicAXML for IFCcompatible BIM software such as Revit MEP. Sijie Zhang et al. [13] conducted a review of the safety regulations applicable to a BIM model of a construction process. Review of 
the potential risks arising from the construction process did not take into account the design stage. Scaffolding was installed throughout the automation as well as safety devices to solve this problem. Sager Malsane et al. [14] studied the IFC schema to propose measures to increase the potential of the UK regulatory review through localization of specific terms in the United Kingdom. The researchers attempted to improve interoperability by the reconstruction of the IFC structure and the applied model.

\subsection{The Domestic Korean Research of Building Code Checking}

Inhan Kim et al. [15] conducted research on building code checking based on safety regulations for super-tall buildings. Using an Application Program Interface (API) of the Solibri Model Checker (SMC), Kim et al. studied the development of the ruleset in the code checking system and the development of an evacuation elevator and safety evacuation zone sector utilizing the IFC Pset. Junho Choi [16] derived entries based on the building permission regulation checklist and proceeded with building code checking using Pset of the IFC. Choi determined whether to use entries in the living room space by random checking based on a defined Pset. Hyeonsu Lee et al. [17] analyzed the humanreadable language sentence in the form of building code objects and building regulation properties the associated functional conversion classification, and the classification items as pseudo code of the previous stage of the system functions. Lee et al. showed the possibility of utilizing building code checking from a variety of programs by establishing an online database for derived entries and transformed codes.

\subsection{Summary}

The result in Table 1 indicates the limits of the target scope and the varieties of methods, such as the adopted standards of codes in using IFC Pset, of code checking. In addition, the confusion among users and application developers regarding different programs, different formats, and types of information representation results in missing information, which is disadvantageous for any project or sector. Therefore, an objective standard based on the IFC open format is required for improving building code checking and information interoperability for the construction industry. This study is to establish an open BIM-based predefined specification for the legality system that would provide an enhanced process for exchange of information by eliminating ambiguity within the review criteria and increase the reliability and interoperability of the building code checking system.

\section{Table 1. Literature review}

\begin{tabular}{|c|c|c|c|}
\hline Sector & Research & Target & Method \\
\hline \multirow[t]{3}{*}{ Korea } & $\begin{array}{l}\text { Development of Rule-based } \\
\text { Checking Modules for the } \\
\text { Evacuation Regulations of } \\
\text { Super-tall Buildings in } \\
\text { Open BIM Environments }\end{array}$ & Evacuation & $\begin{array}{l}\text { - Development of SMC } \\
\text { API ruleset. } \\
\text { - Additional attribute } \\
\text { information utilized by Pset } \\
\text { based on ruleset. }\end{array}$ \\
\hline & $\begin{array}{l}\text { A Study on the } \\
\text { Development of Code } \\
\text { Checking System for } \\
\text { Building Administration } \\
\text { Process Applying Open } \\
\text { BIM-based Process }\end{array}$ & $\begin{array}{l}\text { Building } \\
\text { Permission }\end{array}$ & $\begin{array}{l}\text { - Entries derived through } \\
\text { the licensing checklist. } \\
\text { - Additional attribute } \\
\text { information utilized by Pset } \\
\text { based on entries. }\end{array}$ \\
\hline & $\begin{array}{l}\text { A Logical Rule-based } \\
\text { Approach to the Korea } \\
\text { Architecture Code }\end{array}$ & $\begin{array}{l}\text { Building } \\
\text { Permission }\end{array}$ & $\begin{array}{l}\text { - Development of } \\
\text { translation process of } \\
\text { converting regulation into }\end{array}$ \\
\hline
\end{tabular}




\begin{tabular}{|l|l|c|l|}
\hline & $\begin{array}{l}\text { Sentences for BIM-enabled } \\
\text { Design Assessment } \\
\text { Systems }\end{array}$ & $\begin{array}{l}\text { specific computer-readable } \\
\text { format with logical rule- } \\
\text { based mechanism. }\end{array}$ \\
\hline Overseas & $\begin{array}{l}\text { LicA: A BIM based } \\
\text { automated code-checking } \\
\text { application for water } \\
\text { distribution systems }\end{array}$ & $\begin{array}{l}\text { Distribution } \\
\text { System }\end{array}$ & $\begin{array}{l}\text { - Development of } \\
\text { LicAXML format and code } \\
\text { checking DB. } \\
\text { - Additional attribute } \\
\text { information utilized by } \\
\text { converting the DB to IFC. }\end{array}$ \\
\cline { 2 - 4 } & $\begin{array}{l}\text { BIM-based fall hazard } \\
\text { identification and } \\
\text { prevention in construction } \\
\text { safety planning }\end{array}$ & Safety & $\begin{array}{l}\text { - Create prototypes through } \\
\text { case studies. } \\
\text { - BIM platform that used } \\
\text { code checking. }\end{array}$ \\
\cline { 2 - 4 } & $\begin{array}{l}\text { - Does not use additional } \\
\text { attribute information. } \\
\text { model for automated } \\
\text { compliance checking }\end{array}$ & Fire safety & $\begin{array}{l}\text { - Localization of } \\
\text { specialized structure of the } \\
\text { IFC to the British situation. }\end{array}$ \\
\hline
\end{tabular}

\section{Predefined Specification}

\subsection{Composition}

The predefined specification outlines the standards of information exchange between authors for creating a BIM model and for developers to create programs. A predefined specification that uses the IFC format ensures objectivity and defines the bases for the correct information to be included in the BIM model and the corresponding IFC information to be extracted from the BIM model for the regulation check and building code checking system. The purpose of the predefined specification is to improve reliability and interoperability during information exchange. In addition, in the case where IFC structural objects and properties do not already contain those of the Korean local building codes, this development provides a solution for Korea's most-used BIM modeling tool, Autodesk Revit2015. The predefined specification is created through deriving objects from a mapping table and is configured as seen in Figure 1.

Data for three variables such as Property Name, Property Definition, and Related Objects \& Regulation are collected and reorganized under the IFC format. Related Objects \& Regulation determine the checking priority and reorganization of the IFC structure following the IFC $2 \times 3$. This predefined specification provides an applicable modeling method that can be used with Autodesk Revit2015 per the reorganized IFC structure. The method is then matched and confirmed using BIM Vision. 


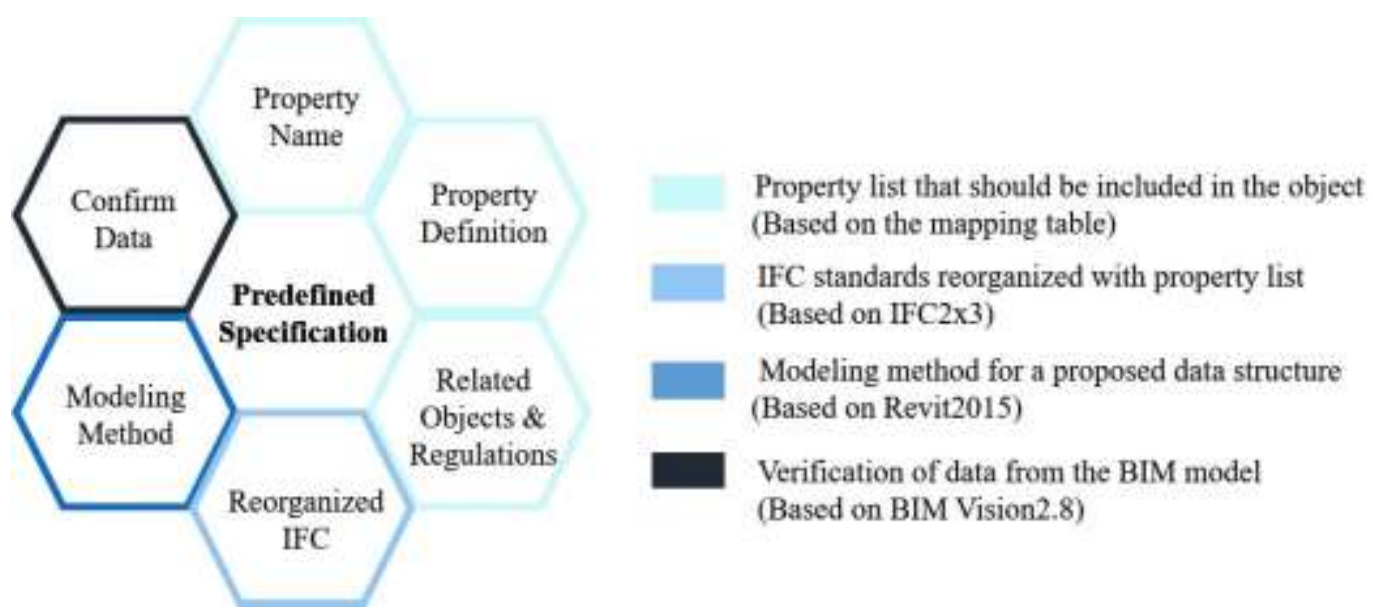

Figure 1. Configuration and Entries of the Predefined Specification

\subsection{Mapping Table}

The IFC data structure and national building codes that are currently available, as mentioned earlier, are defined as properties, objects and other types of construction objects. Korean regulation has many characteristics of a referencing method. This causes arbitrary user interpretations, thus generating differences between criteria. For this reason, it is difficult to easily develop an objective building code checking. To solve this problem, identifying the structure of the national building regulations and establishing a classification based on the IFC standard system are needed to proceed with structural mapping and allow for the exact specification of information to be derived.

The result of mapping this IFC structure is shown in Figure 2. This mapping table consists of properties and objects that exist in the regulations with a dividing step-list, such as article, paragraph and subparagraph. The mapping table is established to connect the building codes sentences into an IFC structure.

Information for building codes sentences that can be extracted into the mapping table are, for example, objects, checked functions, related regulations, and external information derived from the classification criteria of the 2010 "National architectural BIM application guide" authorized by the Ministry of Land, Transport and Maritime Affairs [18]. Within the mapping table, objects are then divided into Spatial-Objects and PartsObjects. The term "Spatial-Object" implies a range of spaces such as floor spaces, areas, and rooms. The term "Parts-Object" implies an object in the physical form, such as a construction element. The properties of the Objects are divide into four entries: Identified Properties, Shape Properties, Physical Properties, and Reference Properties.

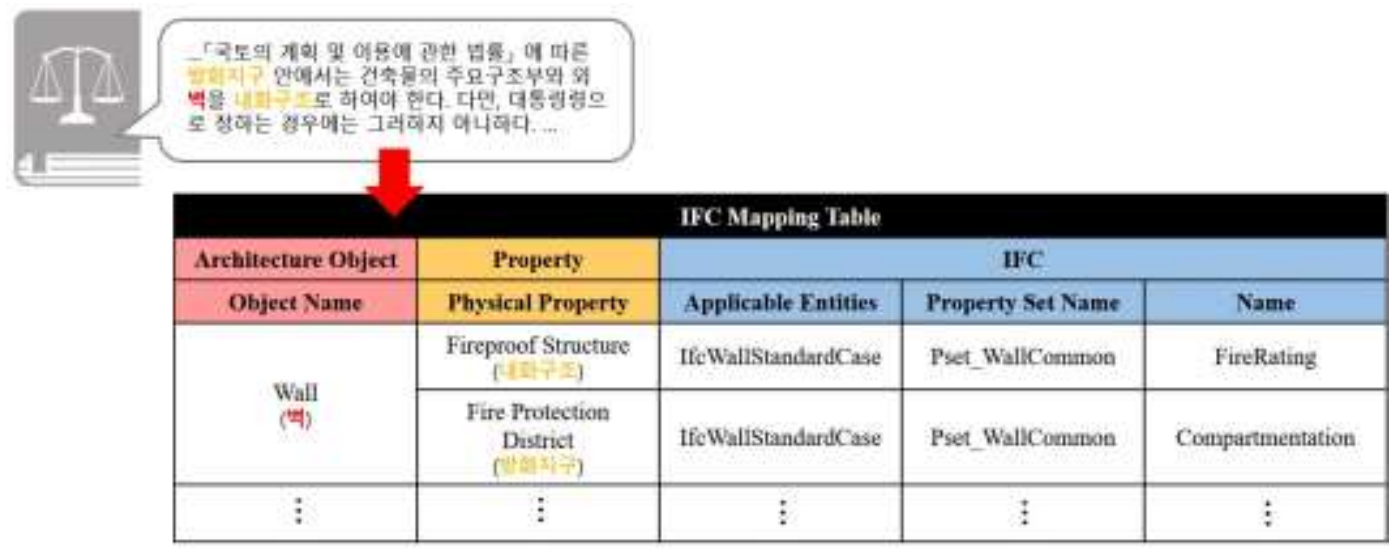

Figure 2. IFC Mapping Table (ex. Wall) 


\subsection{Reorganized IFC}

The most important part of the preparation of the predefined specification is the "Reorganized IFC" to define the specifications of the information itself. This process involves analyzing cases of differences in the IFC data structure between the BIM data and the property using the IFC Pset. The authors had to provide input methods with the consideration of the property and the objects existing in the IFC $2 \times 3$ structure to prevent duplication of the information. In addition, a review of current technical measures that do not support entries through the "Remarks" column is presented. The "Remarks" case is illustrated in the Figure 3.

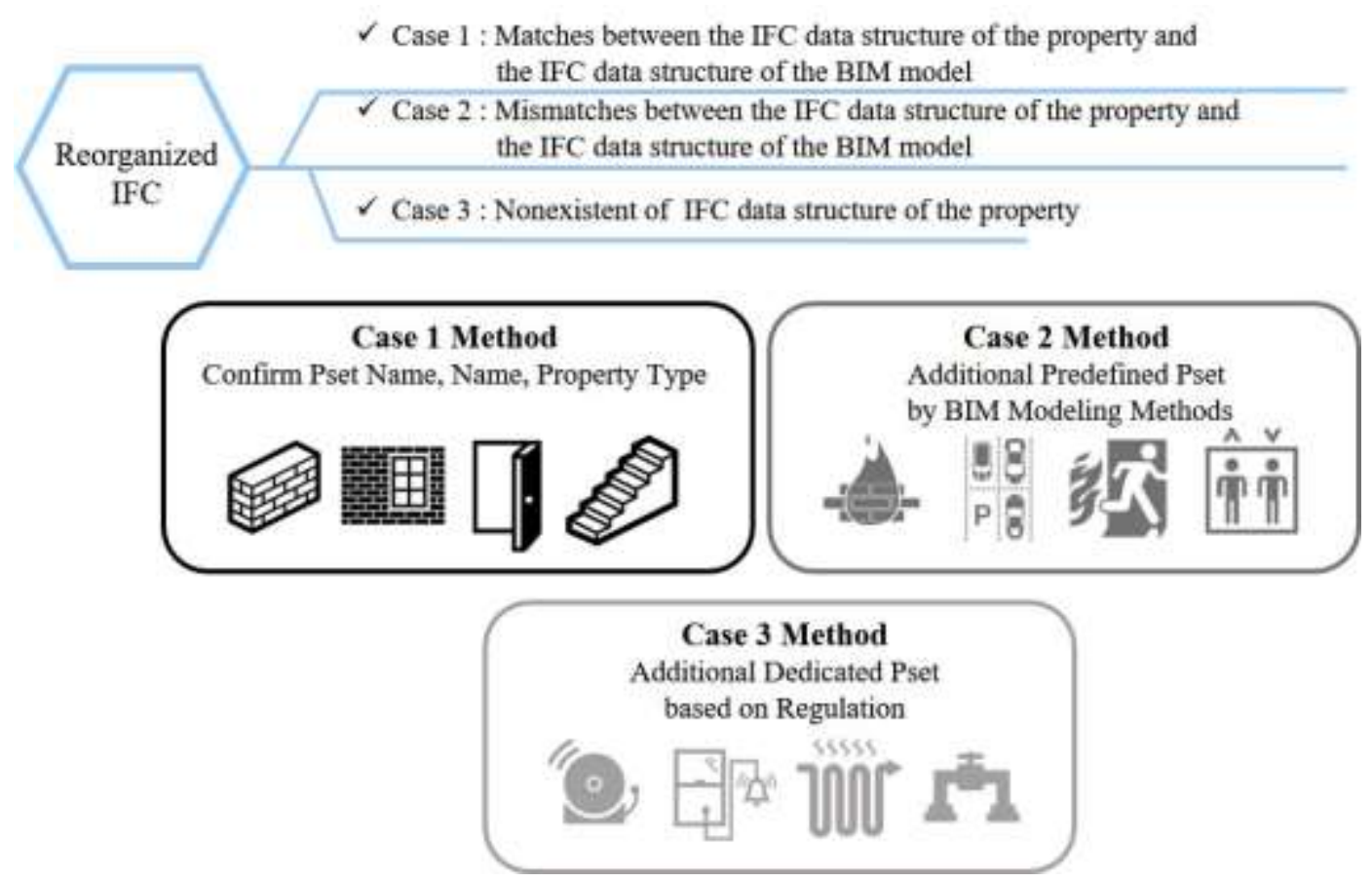

Figure 3. "Remarks" Cases and Methods

The base building object, such as the main structural members, are applicable to Case 1. The Case 1 method is to check the object for the IFC name and the IFC type name followed by the IFC value to examine whether that information is BIM process compatible. In Case 2 and Case 3, it was not possible to input the property because the current technology does not support the property. However, this issue was later addressed by the IFC structure update and BIM modeling. Suggesting ways to input the property as much as possible in the existing structure IFC $2 \times 3$ is currently in the predefined specification. In this case, the object is corresponding to the firewall, secure evacuation zone, evacuation lift, etc. Furthermore, the majority of MEP objects is utilized as a library included in Case 3. Case 2 presents a method within BIM modeling and is an additional attribute information input measure. Case 2 shows the compared data of the IFC data model structure and reviews the interoperability of the BIM information. Case 3 has no data structure in IFC $2 \times 3$ and proposes additional attribute information used in the Pset in accordance with the regulations criteria and BIM modeling method as in Case 2.

Figure 4 shows a difference in the IFC data structure between Revit2015 and IFC $2 \times 3$. This difference could be solved with additional information by IFC conversion using the IFC Parameters Upgrade developed by the Singapore Building \& Construction Authority (BCA). When Revit2015 exports IFC, ambiguous objects are usually extracted into "IfcBuildingElementProxy", which can be changed using the IFC Parameters Upgrade. 
The IFC Parameters Upgrade serves to increase the interoperability of the IFC data and provides input blanks in the Revit property such as "IfcExportAs" and "IfcExportType".

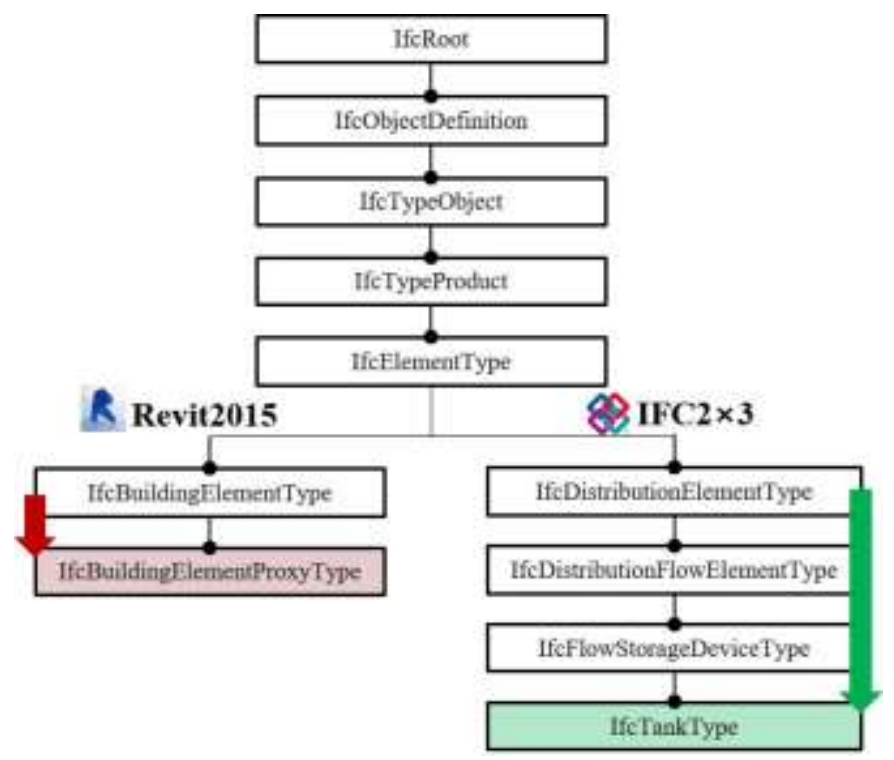

\section{Figure 4. Difference in the Data Structure of Revit2015 and IFC2x3 (eg. Tank)}

\subsection{Development Verification}

This part of the research checks that the data derived is compatible and in line with the structure developed in the predefined specification through the IFC file. At this time, the authors assume that it is difficult for public users to analyze and review the IFC Schema directly. A method to improve understanding of the results is confirmed using the BIM Vision program. BIM Vision is a freeware IFC model viewer that allows users to view the virtual models from CAD systems like Revit, ArchiCAD, Advance, DDS CAD, Tekla, Nemetschek, VectorWorks, Bentley and others, without requiring the commercial licenses or viewer software of these systems. BIM Vision visualizes BIM models created in IFC $2 \times 3$ [19]. Using the plug-in function in BIM Vision to build the interface of the predefined specification in this study enables users to easily test IFC files. The predefined specification interface was built using BIM Vision API and Visual Studio C\# and is shown figure 5 .

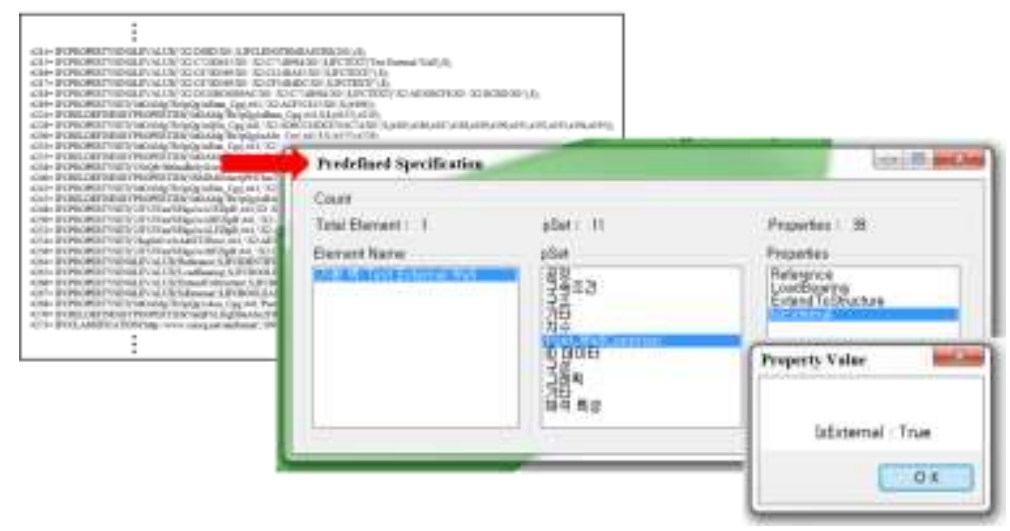

Figure 5. Predefined Specification Interface 


\subsection{Documentation of the Predefined Specification}

The predefined specification summary and an output document produced based on the suggested method above are shown in Figure 6 . The predefined specification can be managed such that content can be added and deleted in accordance with the amended regulation.

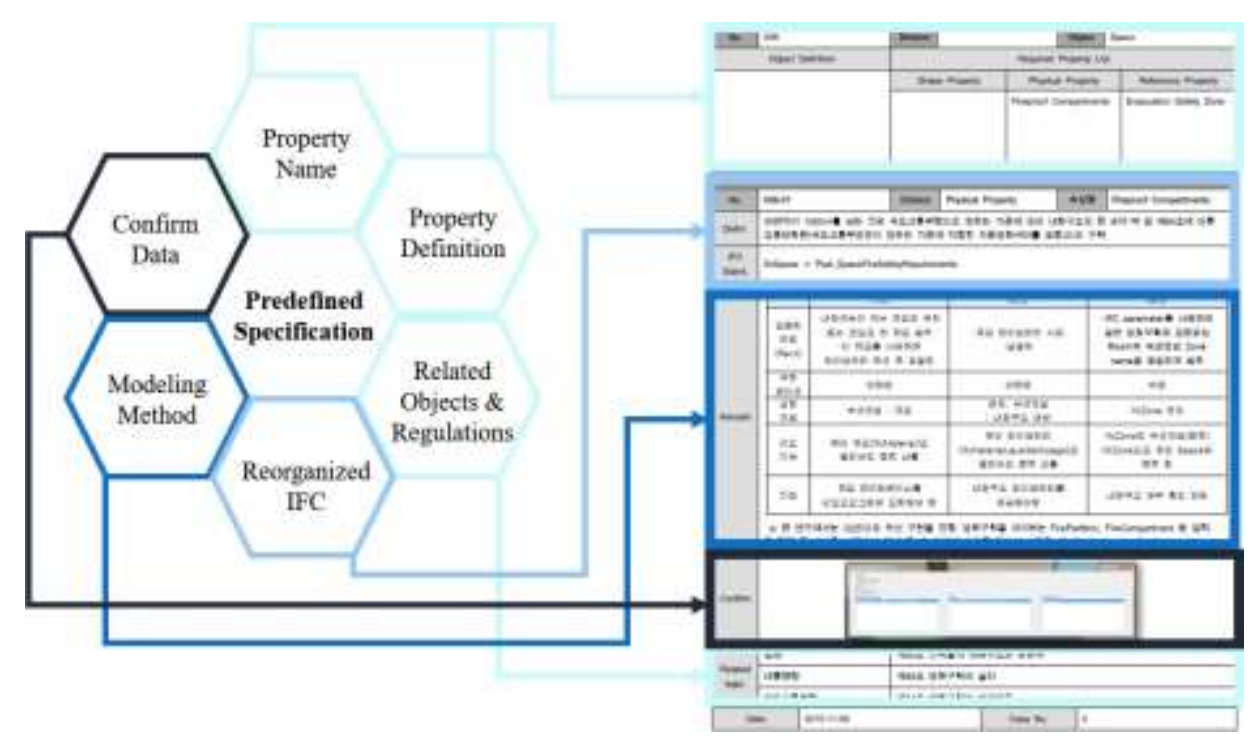

Figure 6. Document Produced using the Predefined Specification

\section{Usage Scenarios}

The purpose of the predefined specification is to improve the reliability of the building code checking system and to improve information interoperability between the BIM model and the building code checking system. Improving interoperability will allow for a scheme that supports modeling definition and program development according to the predefined specification.

Figure 7 shows concisely the overall utilization of the predefined specification. When developers create building code checking programs, they should determine whether the building code is valid for use as the properties of the BIM model with an object through the predefined specification. When a user creates a BIM model, this can also be a method where information required by the building code checking system is entered via a valid modeling guide to the BIM model. By entering and using the predefined information in advance, this can thus achieve better accuracy between the BIM model, building code checking system, and users. In addition, the reliability of the information is improved because the program data is based on the IFC standard.

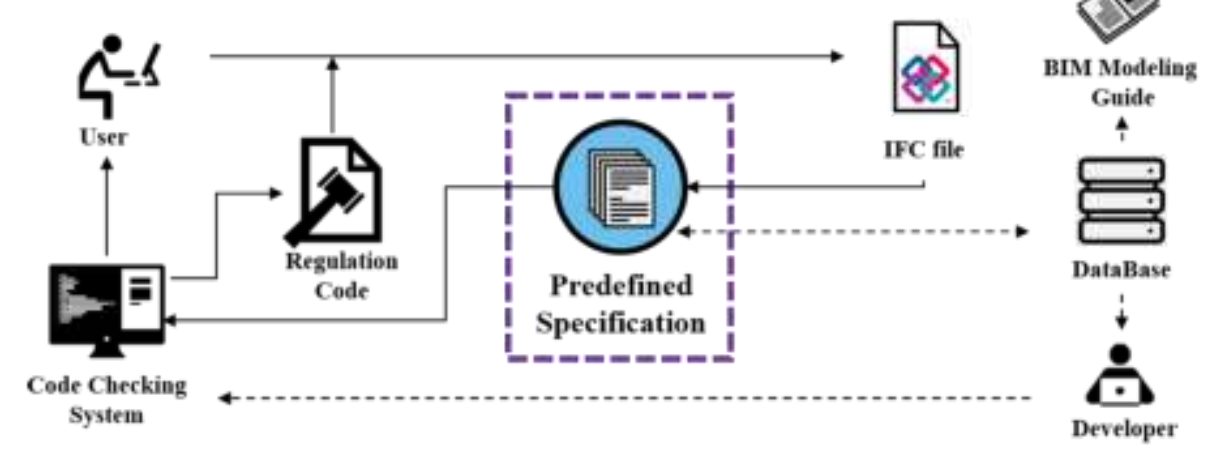

Figure 7. Utilization Scenario of the Predefined Specification 
Furthermore, below is an extended usage scenario with KBim Assess-Lite, a rule-based BIM model code checking software that assesses the quality of the IFC. KBim AssessLite provides the text of select code articles from the Korean Building Act, its enforcement decrees, and the regulations associated with them. Rules are defined and managed with building code checklists based on those currently used in actual architectural firms. The rules are based on the predefined specification, and the system library functions and the scripts are generated by the rules. Figure 8 shows the results of the code checking as exemplified in the "Fireproof Compartments" of Figure 6 and the functions of KBim Assess-Lite [20].

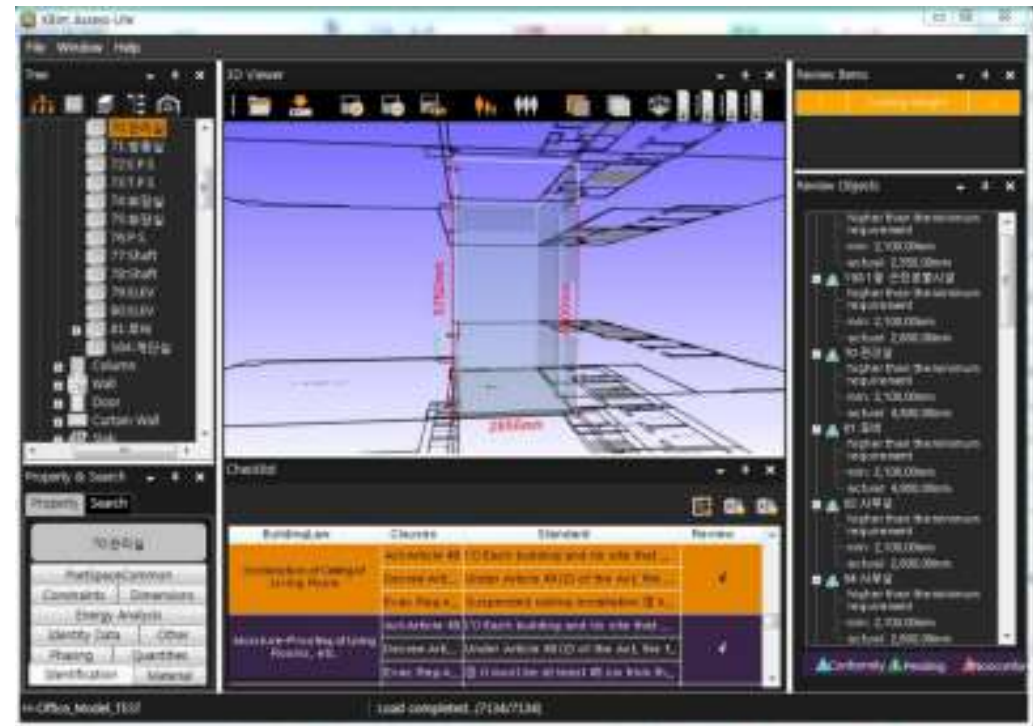

Figure 8. KBim Assess-Lite (eg. Ceiling Height of Fireproof Compartments)

If the standards are established and a baseline of information is managed in advance, this can effectively minimize the problems caused by different data structures between Korean regulation and IFC as well as solve the problem of interoperability with regulatory review data among various modeling software.

\section{Conclusions}

Greater proportions of BIM models in the building industry require greater BIM model design quality and quality checking. The importance of applying BIM to the construction industry is being increasingly stressed because of the policy for compulsory development and supply of BIM for public orders that was introduced by the Public Procurement Service in 2016. As a construction data platform, and not an aggregate of information created in the construction industry, BIM provides all the behaviors and techniques to process and use architectural and construction information depending on the needs of users. Building code checking systems utilizing BIM models will be an essential element in both national and international building administrative procedures in the future. However, it is impossible to include all information regarding national building codes into the international standard IFC. Accordingly, the issue to efficiently utilize building code information in a BIM model is becoming more and more important.

This paper aims to improve the interoperability and reliability of information in the building code checking system with the use of a BIM model and to propose a predefined specification of information extraction between the BIM model and Korean regulations. The authors analyzed the Korean regulation of the "National architectural BIM application guide" and derived objects and properties that were required for building code 
checking. Derived objects and properties identified by the IFC $2 \times 3$ structure were then processed through a mapping table. Creating a predefined specification based on the mapping table and documenting the specification by adding a visualization entry using BIM Vision plug-in interface will help users understand the process and output. The predefined specification could be utilized in the implementation of modeling and programming guidelines to increase interoperability and, as a result, increase the reliability of the building code checking system.

The range of the predefined specification can be expanded using a set of processes as exemplified in this study. Utilizing the information of the various fields of IFC will save time required for building code checking and will aid in improving productivity during construction.

\section{Acknowledgments}

This paper is a revised and expanded version of a paper entitled [Development of openBIM-based Interoperability System for Code Checking System] presented at [GST 2016, Jeju, Dec 20, 2016].

This work was supported by the National Research Foundation of Korea (NRF) grant funded by the Korea government (MSIP) (No. 2015R1A2A2A01008315).

This research was supported by Basic Science Research Program through the National Research Foundation of Korea (NRF) funded by the Ministry of Science, ICT \& Future Planning(NRF-2016R1C1B1014915)

\section{References}

[1] J. Choi, J. Choi and I. Kim, "Development of BIM-based evacuation regulation checking system for high-rise and complex buildings", Automation in Construction, vol. 46, (2014), pp. 38-49.

[2] Y. Kim, H. Kim and M. Kim, "A Study on the Ranging of Phased BIM Introduction Into the Architectural Information System", Journal of the Korea Academia-Industrial cooperation Society, vol. 17, no. 10, (2016), pp. 131-138.

[3] C. Zhang, J. Beetz and M. Weise, "Interoperable validation for IFC building models using open standard" Journal of Information Technology in Construction, vol. 20, (2015), pp. 24-39.

[4] C. Eastman, P. Teicholz, R. Sacks and K. Liston, "BIM Handbook: A Guide to Building Information Modeling for Owners, Managers, Designers, Engineers, and Contractors", John Wiley \& Sons, Hoboken, NJ., (2008).

[5] C. Jo, "A Study on Information Systematization of Detail Drawings for Connectivity between BIM Libraries and Technical Contents based on Information Framework", Journal of the Korea AcademiaIndustrial cooperation Society, vol. 17, no. 10, (2016), pp. 54-60.

[6] J. Choi and I. Kim, "Development of Check-list for BIM Based Architectural Design Quality Check", Transactions of the Society of CAD/CAM Engineers, vol. 18, no. 3, (2013), pp. 177-188.

[7] G. Lee, "What information can or cannot be exchanged?", Journal of Computing in Civil Engineering, vol. 25 , no. 1, (2010), 1-9.

[8] J. Choi and I. Kim, "Interoperability Tests of IFC Property Information for Open BIM based Quality Assurance", Transactions of the Society of CAD/CAM Engineers, vol. 16, no. 2, (2011), pp. 92-102.

[9] buildingSMART, “Open Standards 101", http://www.buildingsmart.org/standards/technicalvision/open-standards-101, accessed on March 4, 2016.

[10] I. Kim, J. Park, C. Park, J. Jung and S. Choo, "BIM in Architecture: Design and Engineering", Kimoondang, Seoul, (2014).

[11] buildingSMART, "IFC Solutions Factory", http://www.blis-project.org/IAI-MVD, accessed on March 4, 2016.

[12] P. João and M. André, "Lica: A BIM based automated code-checking application for water distribution systems", Automation in Construction, vol. 29, (2013), pp. 12-23.

[13] Z. Sijie, S. Kristiina, K. Markku, R. Ilkka, C. Eastman and T. Jochen, "BIM-based fall hazard identification and prevention in construction safety planning", Safety Science, vol. 72, (2015), pp. 31-45.

[14] S. Malsane, J. Matthews, S. Lockley, P. Love and D. Greenwood, "Development of an object model for automated compliance checking", Automation in Construction, vol. 49, (2015), pp. 51-58.

[15] I. Kim, J. Choi and G. Cho, "Development of Rule-based Checking Modules for the Evacuation Regulations of Super-tall Buildings in Open BIM Environments", Transactions of the Society of CAD/CAM Engineers, vol. 18, no. 2, (2013), pp. 83-92.

[16] J. Choi, "A Study on the Development of Code Checking System for Building Administration Process Applying Open BIM-based Process”, Master dissertation, Kyung Hee University, (2014). 
[17] H. Lee, S. Park, I. Kim, J. Lee, "A Logical Rule-based Approach to the Korea Architecture Code Sentences for BIM-enabled Design Assessment Systems”, Journal of Korea Design Knowledge, vol. 34, (2015), pp. 101-110.

[18] Ministry of Land, Transport and Maritime Affairs, National architectural BIM application guide, (2010).

[19] BIM Vision, “About BIM Vision”, http://www.bimvision.eu/home/, accessed on March 4, 2016.

[20] I. Kim, "Open BIM based Technological Environment for Building Design Quality Enhancement", Kyung Hee Univ., (2016).

[21] J. Choi and I. Kim, "Development of openBIM-based Interoperability System for Code Checking System”, Advanced Science and Technology Letters, vol. 141 (GST 2016), (2016), pp. 232-235.

[22] H. Cho, J. Jang and Y. Kim, "Development of System Module Based on BIM Technical Contents Data", Journal of the Korea Academia-Industrial cooperation Society, vol. 17, no. 9, (2016), pp. 680-687.

[23] J. Lee, "Implementation of Customized 4D and 5D System based on BIM", Journal of the Korea Academia-Industrial cooperation Society, vol. 17, no. 8, (2016), pp. 55-61.

[24] Y. Kim, H. Kim and M. Kim, "Support plan for introduction of BIM on Small and Medium Architectural firm", Journal of the Korea Academia-Industrial cooperation Society, vol. 17, no. 9, (2016), pp. 669-679.

\section{Authors}

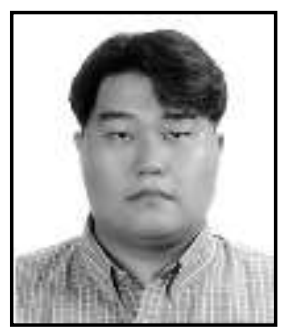

\section{Jungsik Choi}

2001. M.S. in Architectural Engineering, Kyung Hee University 2011. Ph.D. in Architectural Engineering, Kyung Hee University 2013. Postdoctoral Fellow, Lawrence Berkeley National Laboratory (LBNL), USA

2013 Present. Research Professor in College of Engineering, Kyung Hee University

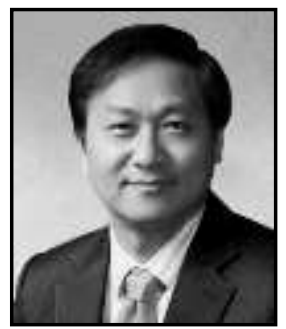

\section{Inhan Kim}

1991. M.S. in Architecture, Cernegie-Mellon University, USA

1994. Ph.D. in Architecture, University of Strathclyde, UK

2008 Present. Founder, Chief Vice Chairman, buildingSMART Korea

1996 Present. Professor in Dept. of Architecture, Kyung Hee University

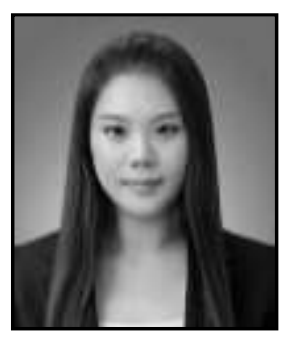

\section{Jongyeon Bae}

2015. B.S. in Architecture, Kyung Hee University

2017. M.S. in Architecture, Kyung Hee University 
International Journal of $u-$ and e- Service, Science and Technology Vol.10, No.8 (2017) 